\title{
Environmental effect of water absorption and flexural strength of red mud filled jute fiber/polymer composite
}

\author{
${ }^{1}$ B. C. Patel, ${ }^{2 *}$ S. K. Acharya, ${ }^{3}$ D. Mishra \\ ${ }^{1}$ Department of Mechanical Engineering, PIET, Rourkela, INDIA \\ ${ }^{2 *}$ Department of Mechanical Engineering, National Institute of Technology Rourkela, Odisha, INDIA \\ ${ }^{3}$ Department of Mfg.Sc. \& Engg, VSSUT, Burla, Sambalpur, INDIA \\ "Corresponding Author: e-mail: drsamirka@yahoo.com, Tel +91-9437248460
}

\begin{abstract}
Natural fibers are considered as a good reinforcement in composite material because of their good mechanical properties and low density. However the main drawback of these fibers is moisture absorption in their outdoor applications. The present investigation is aimed at processing a composite using jute fiber and epoxy resin as matrix and red mud as a filler material. The degradation of the composite mechanical properties such as flexural strength has been studied when it is subjected to different environmental conditions. To increase the adhesion between fiber and matrix material and to increase the moisture resistance chemical surface treatment has been performed on the fibers. The composites flexural strength and moisture resistance with modified fibers have also been investigated. It was found that chemical modification of fibers reduced the overall water uptake of the jute fibers. The flexural strength of the composite with modified fibers increases significantly compared to untreated fibers.
\end{abstract}

Keywords: Jute fiber, Red mud, Alkali treatment, Flexural Strength, Weathering behavior.

DOI: http://dx.doi.org/10.4314/ijest.v4i4.5

\section{Introduction}

Polymeric composites commonly used consist of wide range of particulate and fibrous materials. The growing demand for new materials with specific properties for aircraft, automobile, leisure, electronics and medical industries has led to the development of better and cheaper polymer composites. Natural fibers are of particular interest; especially when weight considerations are fundamental. Environmental awareness today motivates world-wide studies of natural fiber reinforced polymer composite. This is because natural fibers have the potential of serving as alternative for artificial fiber composite (Bledzki and Gassan, 1999; Bogoeva-Gaceva et al., 1980). Accordingly extensive studies on preparation and properties of thermosetting and thermoplastic composite filled with Jute (Mohanty et al., 2000), Sisal (Joseph et al., 1999), Pineapple (Mukherjee et al, 1986), Bamboo (Jain et al, 1992), Kenaf (Nishino et al, 2003) and bagasse fiber (Vazquez et al, 1996) were carried out. These plant fibers have many advantages over glass fiber or carbon fiber like renewable, environmental friendly, low cost, light weight, high specific mechanical performance. In general natural fibers are hygroscopic in nature and they absorb or release moisture depending on environmental conditions. Amorphous cellulose and hemicellulose that present in the natural fiber are mostly responsible for the high moisture absorption, since they contain numerous easily accessible hydroxyl groups which give a high level of hydrophilic character to fiber. The high moisture absorption of the fiber occurs due to hydrogen bonding of water molecules to the hydroxyl groups within the fiber cell wall. This leads to a moisture build-up in the fiber cell wall (fiber swelling) and also in the fiber-matrix interface. This in turn becomes responsible for changes in the dimensions of cellulose-based composites, particularly in the thickness and the linear expansion due to reversible and irreversible swelling of the composites (Rowell, 1997).

Another problem associated with fiber swelling is a reduction in the adhesion between the fiber and the matrix, leading to deterioration in the mechanical properties of the composite (Espert, et al., 2004). A good fiber-matrix bonding can decrease the 
rate and amount of moisture absorbed by the composite as well as improving the mechanical properties (Sanadi, et al., 1997). However in order to overcome this problem, chemical treatment has been considered as a good technique to reduce the hydroxyl group in the fibers. Different chemical treatments such as mercerization or alkali treatment, isocyanate treatment, acrylation, benzoylation, permanganate treatment, acetone treatment, acetylation, silane treatment etc. are reported by several researchers (Maya Jacob John et al., 2008, Joseph, et al, 1996, Joseph et al, 1999). Another term 'filler' is very often used and encompasses a very wide range of materials that plays an important role for the improvement in performance of polymers and their composites. Filler materials are used to reduce the material costs, to improve mechanical properties to some extent and in some cases to improve process ability. Besides, it also increases properties like abrasion resistance, hardness and reduces shrinkage. So, although in fiber reinforced plastics, a judicious selection of matrix and the reinforcing phase can lead to a composite with a combination of strength and modulus comparable to or even better than those of conventional metallic materials, their physical and mechanical properties can further be modified by addition of a solid filler phase to the matrix body during the composite preparation.

Polymer composites containing different fillers and/or reinforcements are frequently used for many applications, in which degradation of mechanical properties when subjected to different environmental condition with use is a prime issue. The present research work is undertaken to develop a new class of natural fiber reinforced polymer composites filled with an industrial waste redmud (waste generated during Alumina production from Bauxite) and to study their mechanical and environmental performance.

\section{Experiment}

2.1 Treatment of fiber: The interfacial bonding between the fiber and the resin matrix is an important element for improving the mechanical properties of the composite. The chemical treatment of fiber aimed at improving the adhesion between the fiber surface and the polymer matrix by modifying the fiber surface and the fiber strength. Out of the available processes for the present case the fiber surface has been modified by alkali treatment. The procedure followed for the present case is similar to the process followed by Acharya et.al (2011) for bagasse fiber and it is found that jute fiber with $5 \% \mathrm{NaOH}$ solution treated for 4 hrs gives maximum strength to the composite. Hence we have used 4 hrs alkali(5\% concentration) treated jute fiber for preparation of the composites for further experimentation.

2.2 Redmud-. Production of alumina from bauxite by the bayer's process is associated with generation of red mud as the major waste material. Depending upon the quality of bauxite the quantity of red mud generation varies from 55-65\% of the bauxite processed this red mud comprises of the oxides of iron, titanium and the silica along with other minor constituents. Since the constituents of red mud comprises of different metal values it is thought worth to reinforce it as a filler material. Red mud used for the present investigation was brought from the aluminum refinery of NALCO located at Damanjori, Koraput,Odisha ,India.Table-1 shows the components of Redmud as per the dry analysis. The size of dust was measured by sheave. As per sheave analysis average size of the dust was 150 microns.

Table 1. Components of red mud

\begin{tabular}{|c|c|c|c|}
\hline Constituents & \% (wt) & Constituents & $\%$ (wt) \\
\hline $\mathrm{Al}_{2} \mathrm{O}_{3}$ & 15.0 & $\mathrm{Fe}_{2} \mathrm{O}_{3}$ & 54.8 \\
\hline $\mathrm{TiO}_{2}$ & 3.7 & $\mathrm{SiO}_{2}$ & 8.44 \\
\hline $\mathrm{Na}_{2} \mathrm{O}$ & 4.8 & $\mathrm{CaO}$ & 2.5 \\
\hline $\mathrm{P}_{2} \mathrm{O}_{5}$ & 0.67 & $\mathrm{~V} \mathrm{O}_{5}$ & 0.38 \\
\hline $\mathrm{Ga}_{2} \mathrm{O}_{3}$ & 0.096 & $\mathrm{Mn}$ & 1.1 \\
\hline $\mathrm{Zn}$ & 0.018 & $\mathrm{Mg}$ & 0.056 \\
\hline Organic C & 0.88 & L.O.I & Balance \\
\hline
\end{tabular}


2.3 Composite preparation: A perspex sheet mold of dimension 130x130x6 mm was used for casting the composite slab. Different group of samples were manufactured with single ,double and triple layers as presented in table-1. Usual hand-lay-up technique was followed for manufacturing the composite. For different layered composites, a calculated amount of epoxy resin(LY556) and hardener(HY951) (ratio10:1 by weight) was thoroughly mixed with gentle stirring to minimize air entrapment. For quick and easy removal of composite slab a mold release sheet was put over the glass plate and mold release spray was applied at the inner surface of the mold wall after it was set on the glass plate. The prepared mixture of epoxy resin, hardener and epoxy resin/hardener/red mud as the case may be was poured into the mold and the mold was allowed to cure at room temperature for 72 hrs. After curing the samples were taken out of the mold and cut to sizes as per ASTM standard for further experimentation.

TABLE-2

DIFFERENT GROUP OF SAMPLES

\begin{tabular}{|c|c|c|c|c|}
\hline Layers & $1^{\text {st }}$ group & $2^{\text {nd }}$ group & $3^{\text {rd }}$ group & $4^{\text {th }}$ group \\
\hline Single & UTF & UTF+RM & TF & TF+RM \\
\hline Double & UTF & UTF+RM & TF & TF+RM \\
\hline Triple & UTF & UTF+RM & TF & TF +RM \\
\hline \multicolumn{2}{|r}{$*$ UTF-Untreated fiber TF-Treated Fiber RM- Red Mud $\quad$ Volume \% of RM-20\% } \\
\hline
\end{tabular}

\section{Experimental procedure}

To find out the effect of environment on mechanical properties the composite samples were subjected to various treatments like: Steam, Saline and Subzero condition. In each condition a set of composites (single, double and triple layer) were tested for various time lengths. The schematic view of the layered composites is shown in Fig.1. Steam treatment was conducted at $100^{\circ} \mathrm{C}$ with $95 \%$ relative humidity. Subzero treatment was conducted at $-23^{0} \mathrm{C}$ and saline treatment was carried out at $5 \%$ concentration. At the end of the treatments $(80 \mathrm{hrs})$ at each condition the dimensions and weight change were measured .Three point bend tests were carried out at room temperature at a cross head speed of $10 \mathrm{~mm} / \mathrm{min}$ as per ASTM standard D3039-76.Composites were tested using a span of $100 \mathrm{~mm}$ in an UTM 201 machine. An average of five tests per sample was performed to report the changes in flexural strength of the composite after they were subjected to different treatments.

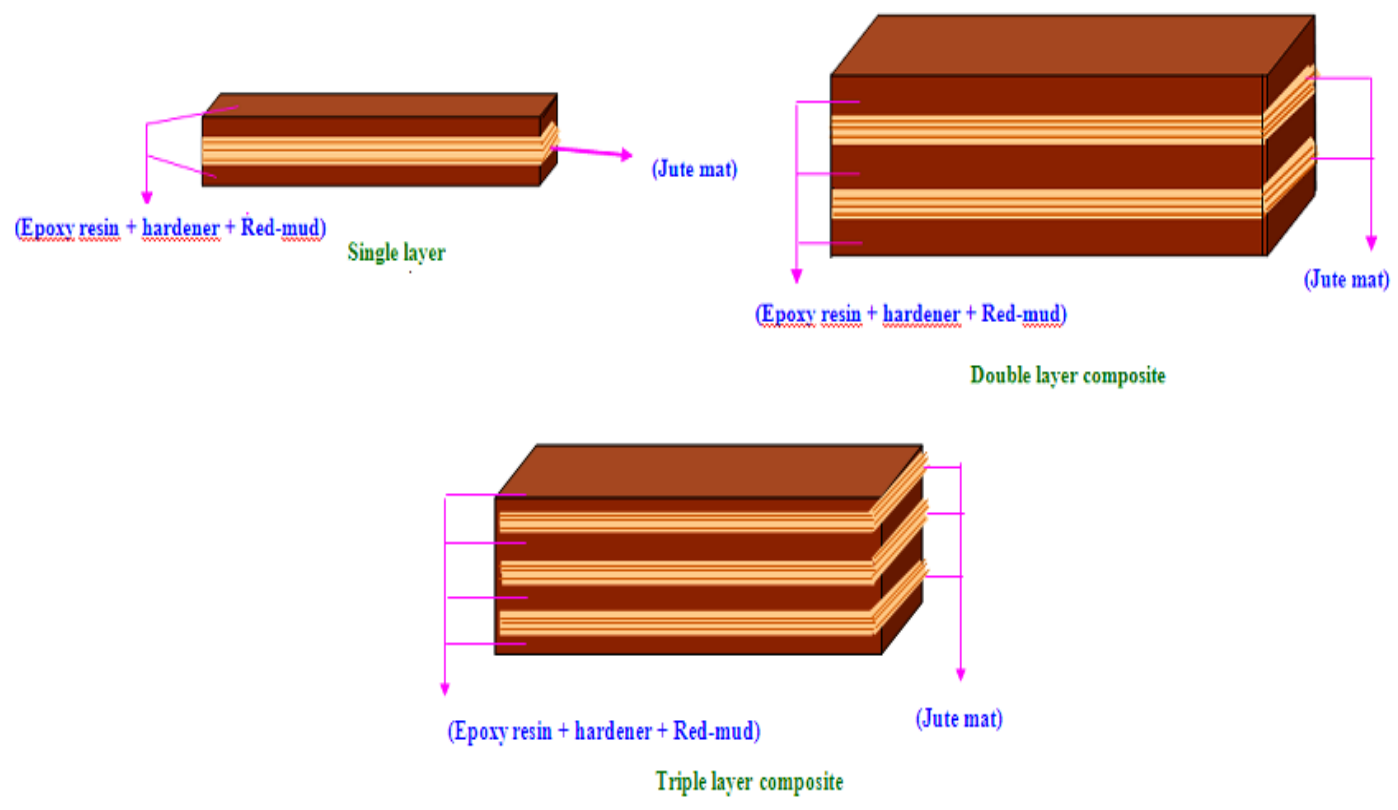

Figure 1. Schematic view of the composites 


\section{Results and Discussion}

Figure 2 to 4 show the water absorption curve showing percentage of weight gain as a function of exposure time in steam, for single, double and triple layer jute composite. In all cases the water absorption process is sharp at the beginning and leveled off for some length of time where it approaches to equilibrium. It is considered that the change of weight gain for all samples is a typical Fickian diffusion behaviour. The composites show almost same water absorption for treated fiber with and without red mud filler for single and double layer composite. But the triple layer composite with red mud show lower water absorption. It is also clear that treated fiber reduced the water uptake capacity of the composite and introduction of red mud in to the composite has some positive effect in the triple layered composite. Also the chemical treatment reduces the hydroxyl group in the cell wall of natural fiber molecules, thus decreasing the water absorption of the composite. The result of water absorption here is in accordance with the previous work by Fraga et al (2006) on their study on Jute fiber unsaturated polyester composite.

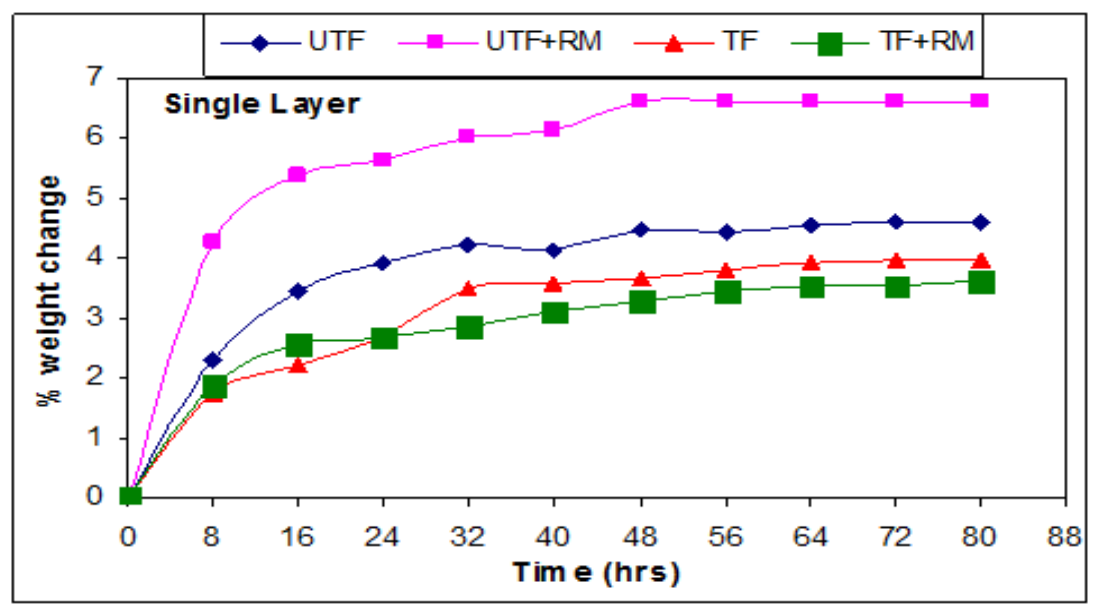

Figure 2. Water absorption behaviour of Single layer Jute Fiber composite under steam treatment

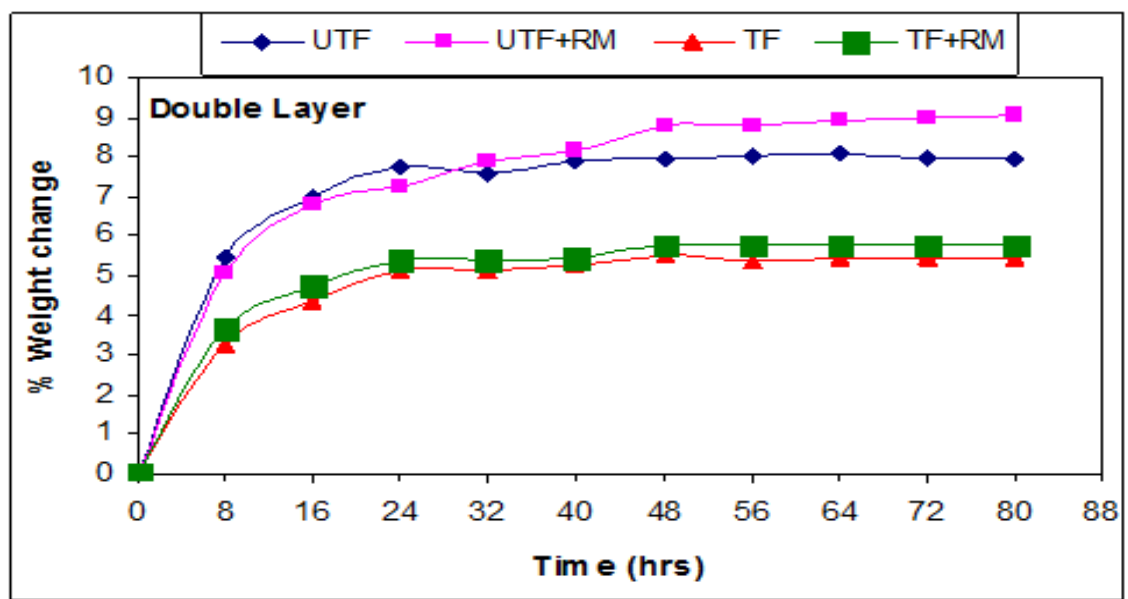

Figure 3. Water absorption behaviour of Double layer Jute Fiber composite under steam treatment 


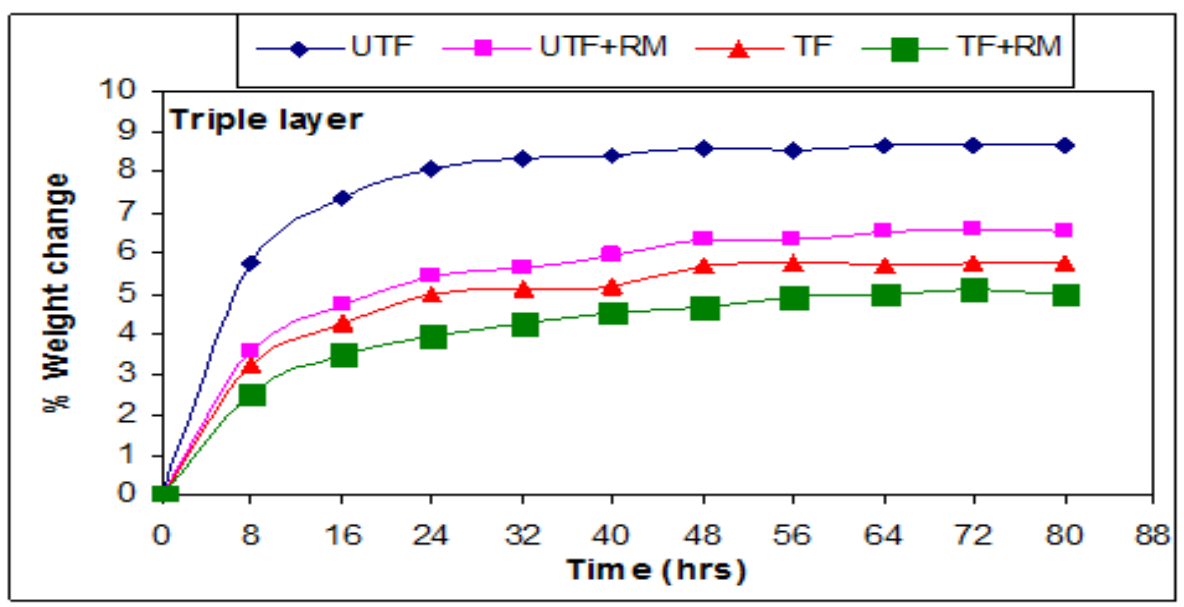

Figure 4. Water absorption behaviour of Triple layer Jute Fiber composite under steam treatment

Figure- 5 to 7 show that percentage of weight gain as a function of time for saline water. Here also the same trend is observed for the composite. For the single layer and triple layer composite the treated fiber with red mud got stabilized within 32-40 hrs of treatment. For double layer composite it got stabilized after 64 hrs of treatment. This might have happened because the exposed surface areas are not protected enough by the filler material; hence the time taken for saturation takes longer time.

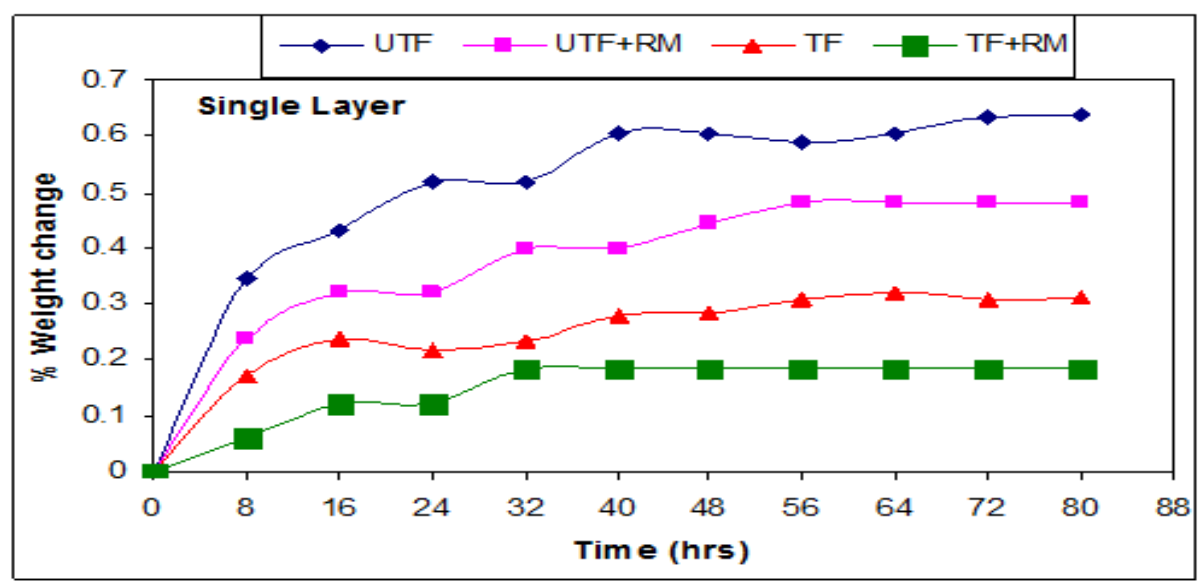

Figure 5. Water absorption behaviour of Single layer Jute Fiber composite under saline water treatment

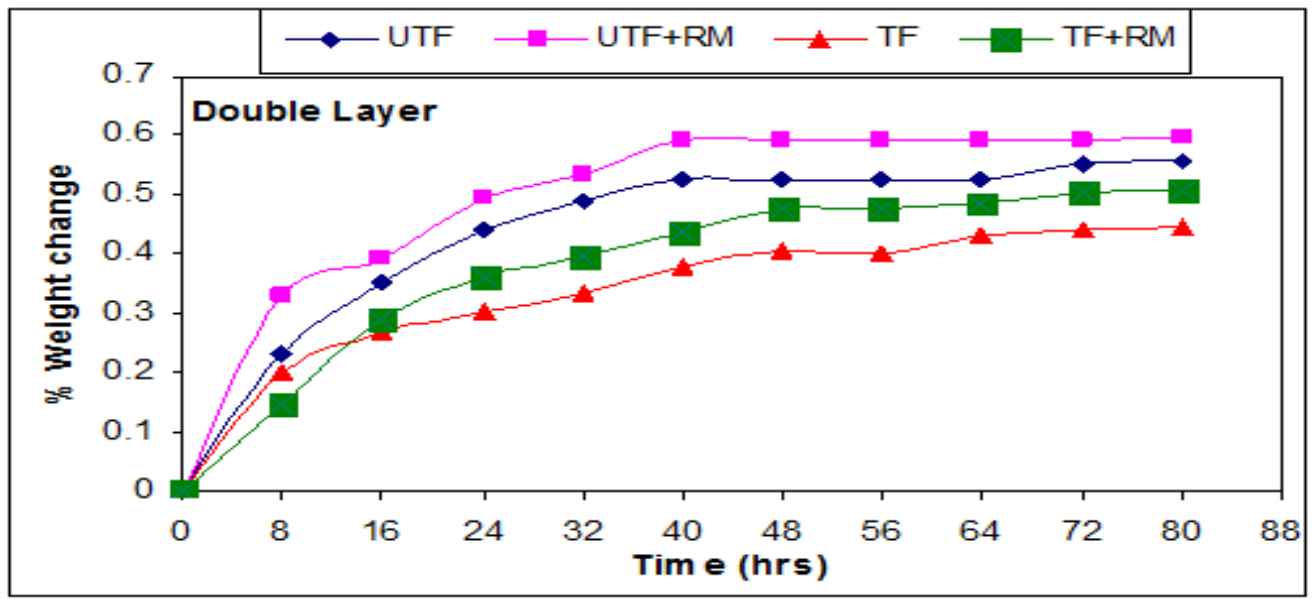

Figure 6. Water absorption behaviour of Double layer Jute Fiber composite under saline water treatment 


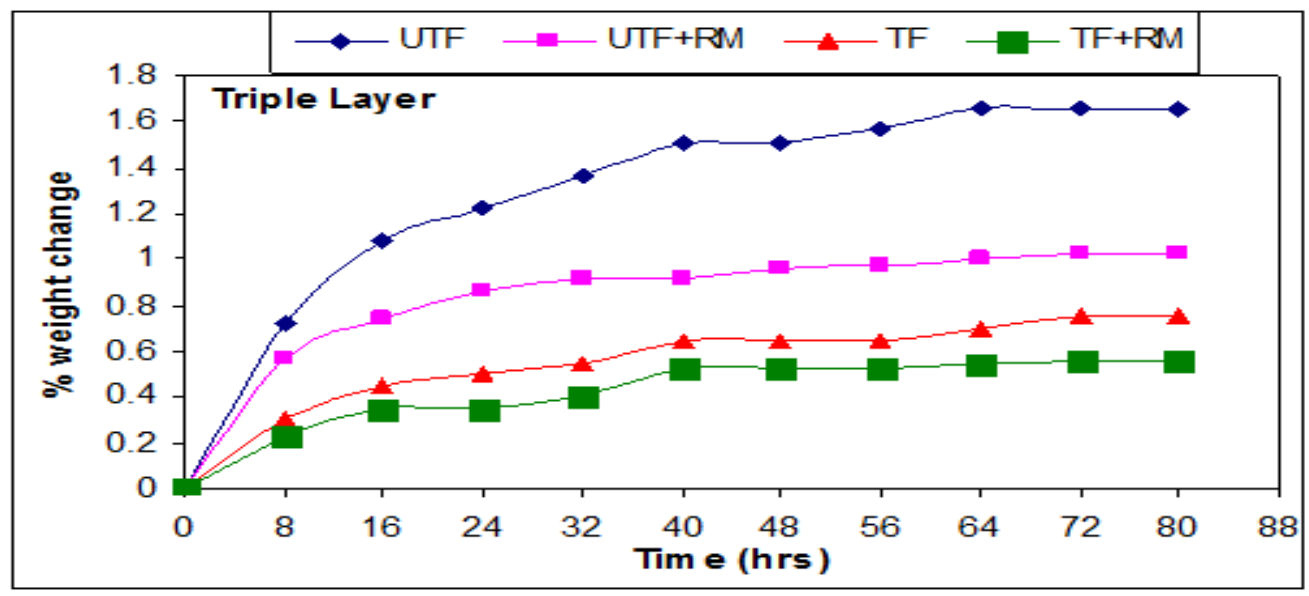

Figure 7. Water absorption behaviour of Triple layer Jute Fiber composite under saline water treatment

Figure-8 to 10 show the percentage of weight gain as a function of time for sub zero condition. Here the water uptake for the composite is much lower in comparison to steam and saline treated composite. It is also seen that the water uptake for treated fibers with red mud samples are higher than without red mud samples. Absorption of small amount of water by the red mud particles may be the possible criteria for this type of behavior of the samples..

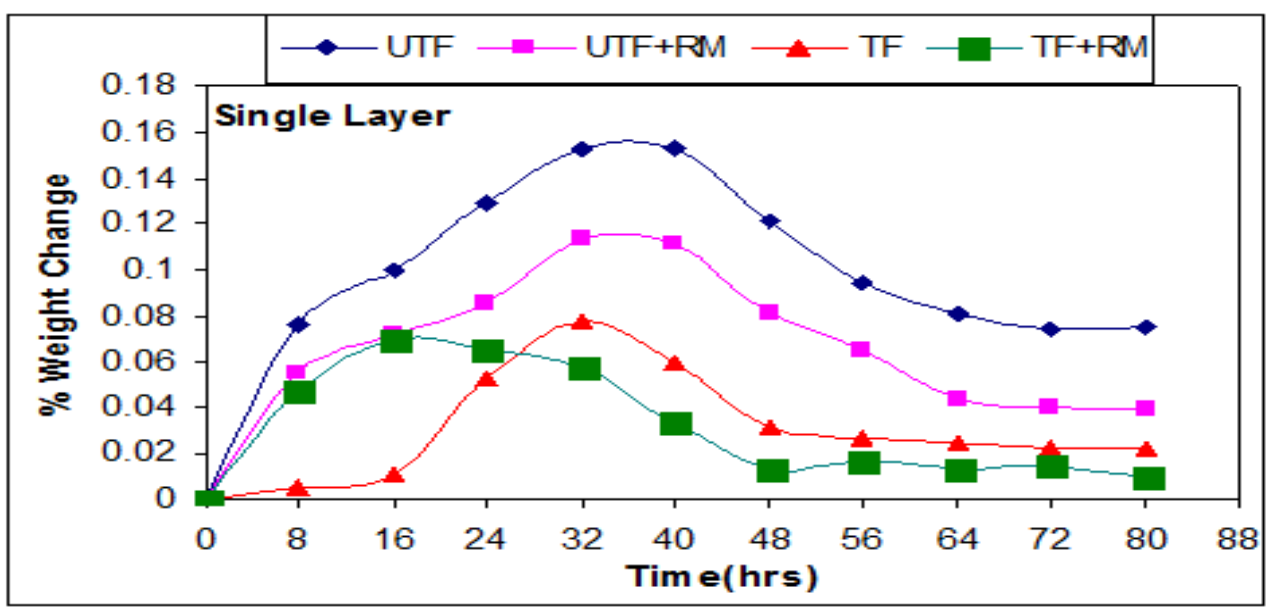

Figure 8. Water absorption behaviour of Single layer Jute Fiber composite under subzero condition

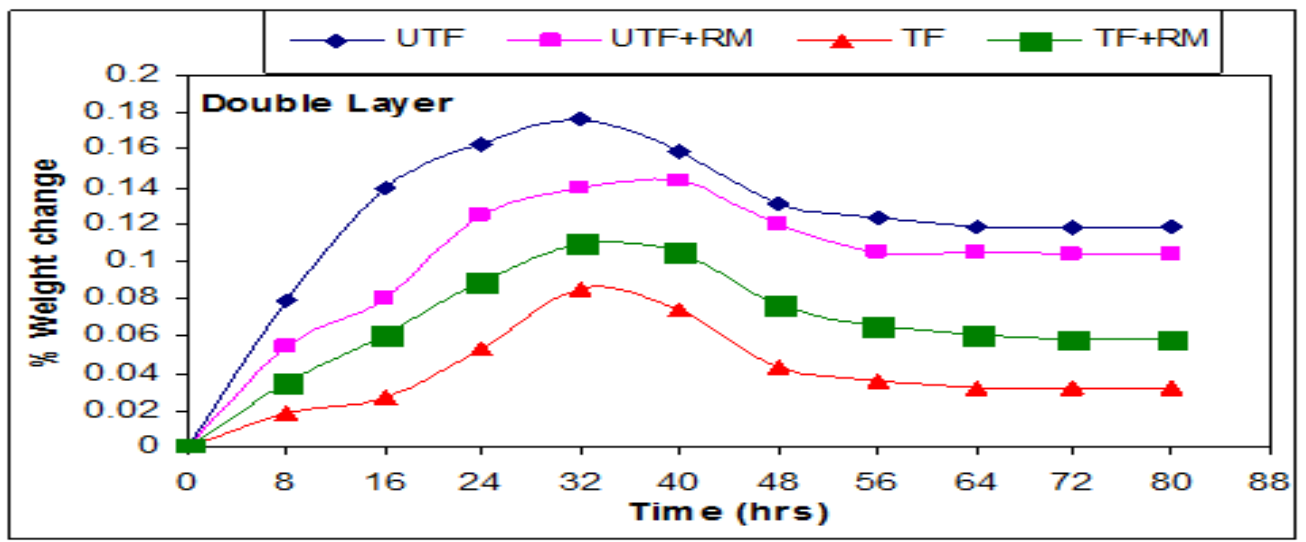

Figure 9. Water absorption behaviour of double layer Jute Fiber composite under subzero condition 


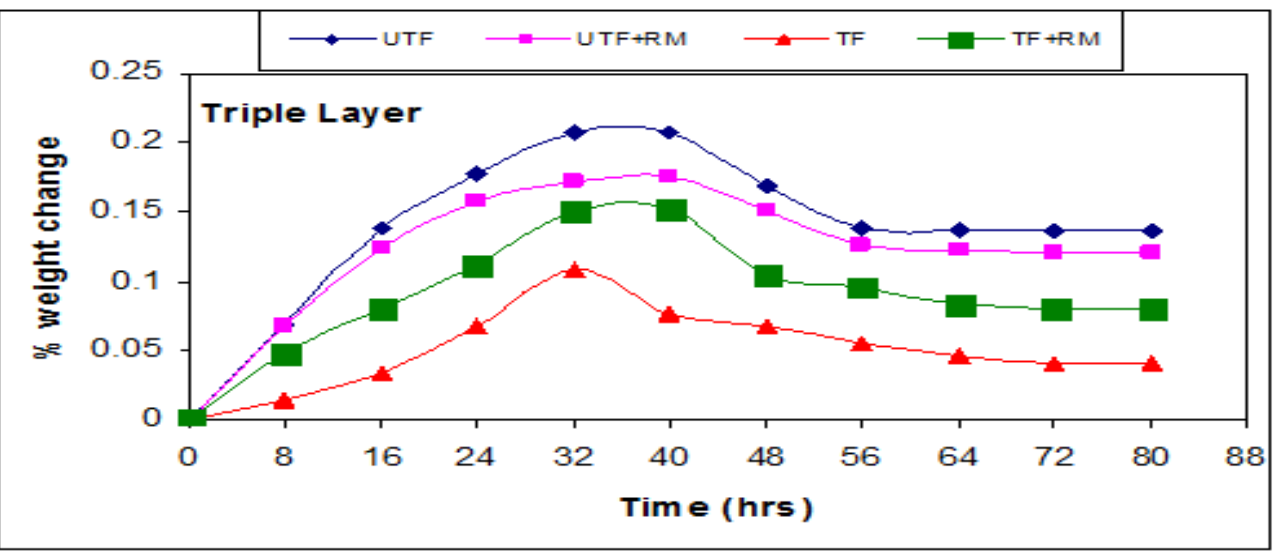

\subsection{Flexural Strength}

Figure 10. Water absorption behaviour of triple layer Jute Fiber composite under subzero condition

Figure-11 to 13 show the flexural strength of composites for single, double and triple layers subjected to different environmental treatments. In all cases it is observed that the composite prepared with red mud and fibers treated with alkali showed maximum improvements. All layered composites showed higher flexural strength value for steam and subzero exposure; however the flexural strength of saline treated composite showed lesser value. This might have happened because during saline treatment not only the moisture absorption takes place but also transport of sodium and chlorine ions do occur leading to some chemical reaction with the jute fiber which finally degrade the strength to certain extent but not so lower than the untreated fibers.

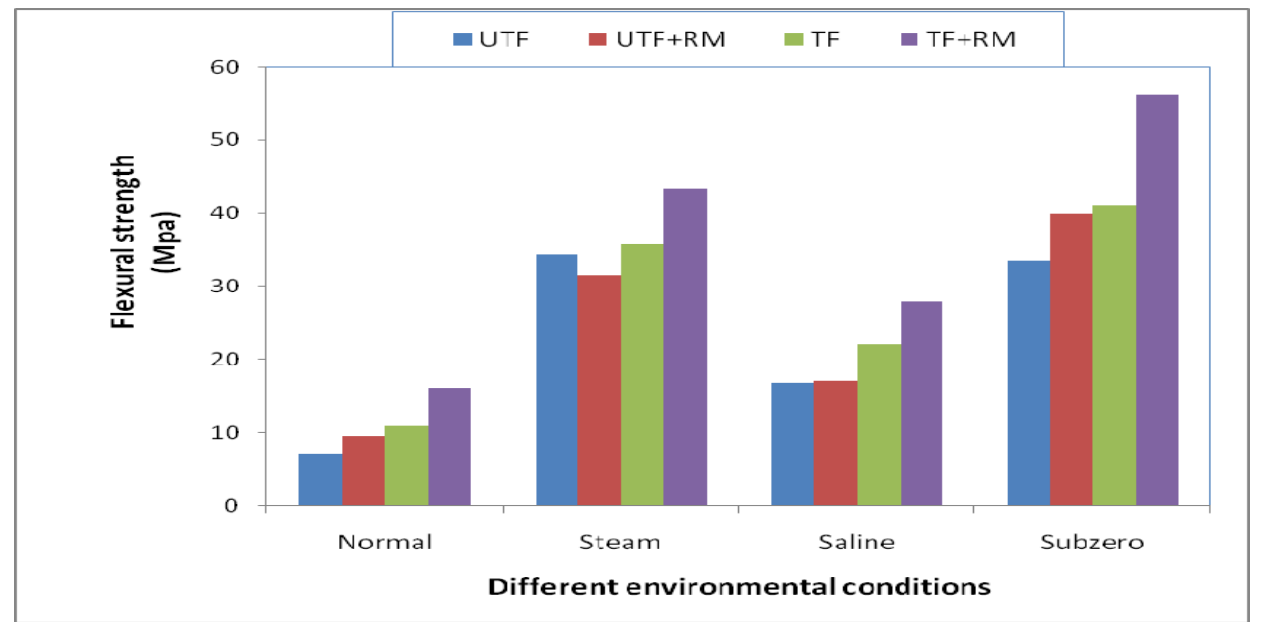

Figure 11. Flexural strength of single layer Fiber composite under different environmental conditions

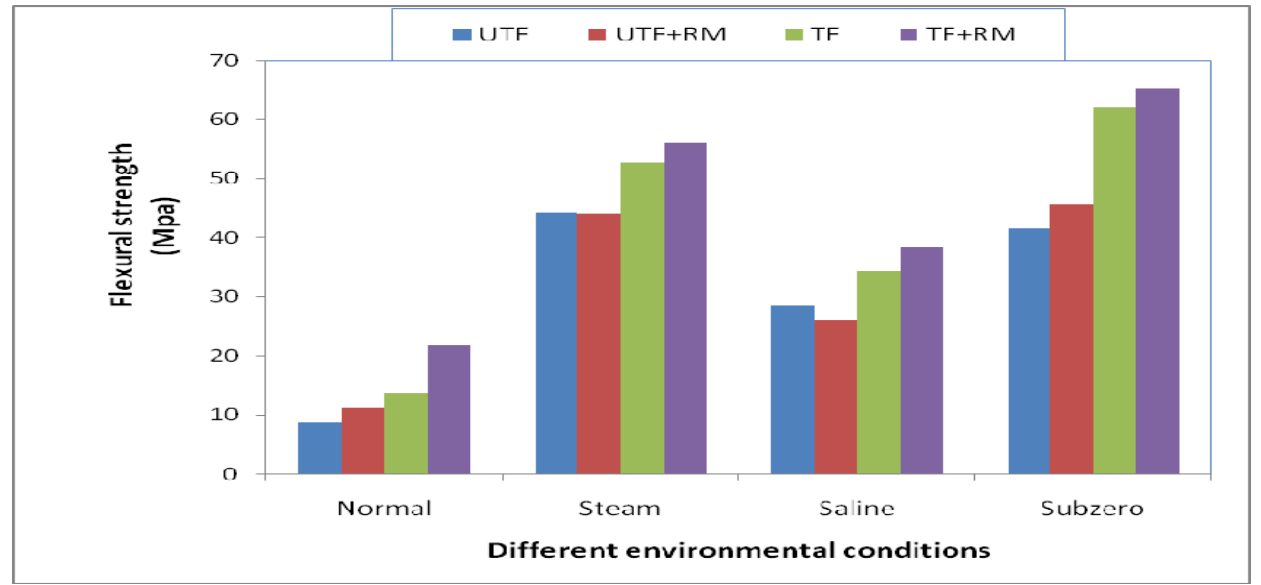

Figure 12. Flexural strength of double layer Fiber composite under different environmental conditions 


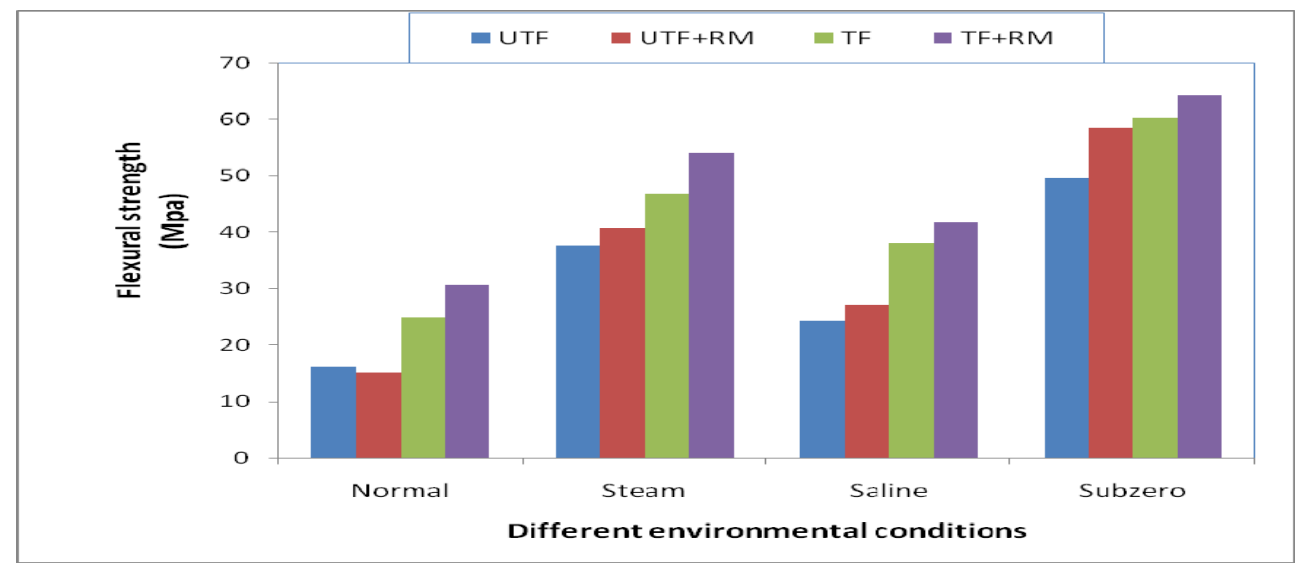

Figure 13. Flexural strength of triple layer Fiber composite under different environmental conditions

Figure-14 show the comparison of the flexural strength of the TF+RM samples for single, double and triple layer composites in various environmental conditions. It is observed in all cases that, the strength of the composite varies when subjected to different environment but in all cases the triple layered composites indicates the highest strength.

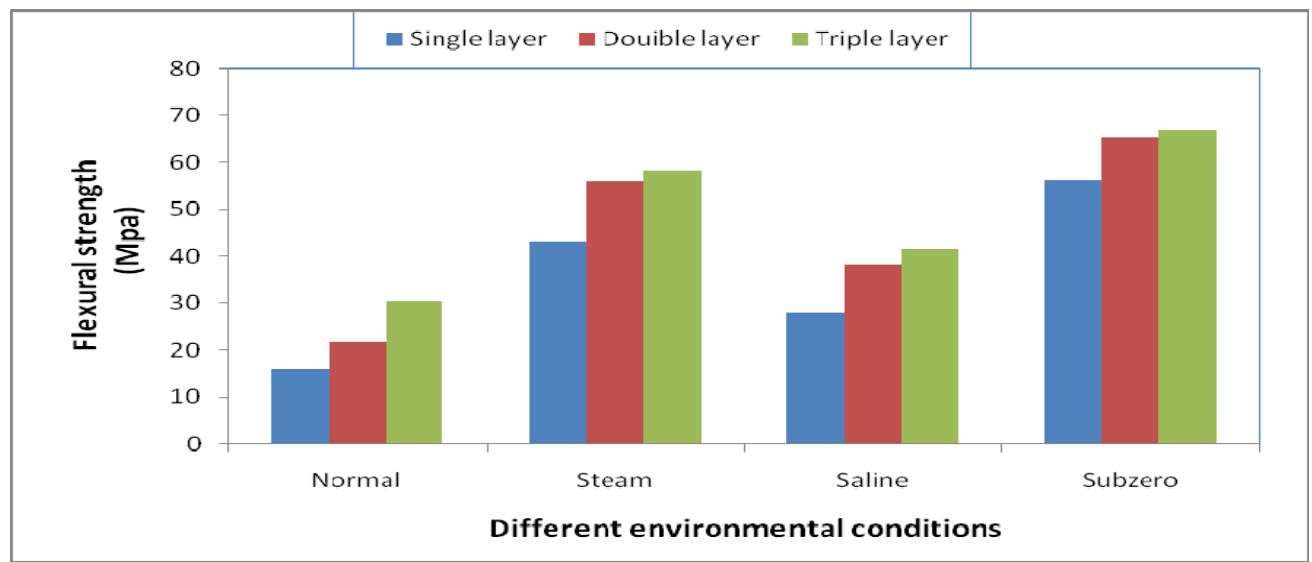

Figure 14. Flexural strength of single, double and triple layer TF+RM composites under different environmental conditions

4.2 Fractrographic Analysis To characterize the morphology of untreated and treated fiber surfaces and the mode of material removal, the samples are observed under scanning electron microscope (SEM) Joel JSM-6084LV. The samples are mounted on stubs with silver paste. To enhance the conductivity of the composite samples, a thin film of platinum is vacuum evaporated onto them before the photographs are taken.

Figure-15(a) displays the flexural strength of the untreated fiber composite in normal condition. Most of the fibers are seen to be broken which indicates a poor fiber matrix adhesion. Matrix cracking is also clearly visible. When the composite is subjected to steam treatment it is seen that most of the fibers fig15(b) have come out from the matrix without breaking. Probably dissolution of cellulose constituent in alkali creates voids in the fiber structure which increases swelling and makes the fiber weaker. Destruction of mesh net work and splitting of fiber in to filament may be the possible cause of failure. 


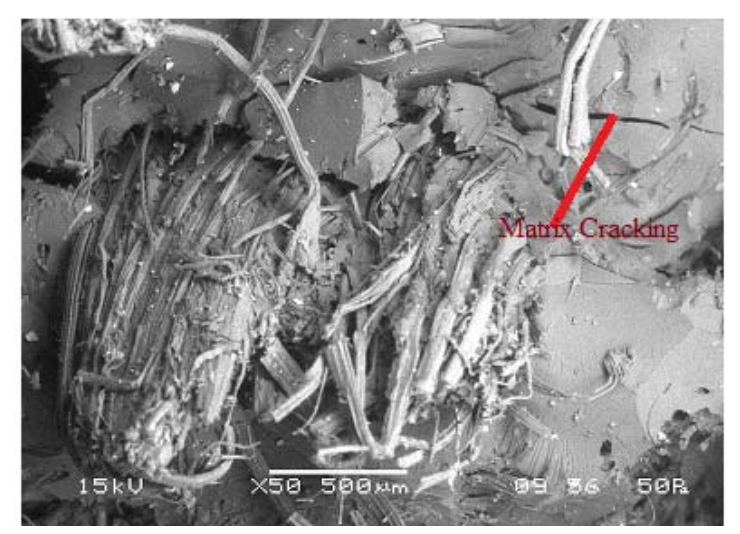

Figure 15(a) SEM micrograph of fractured surface of UTF (single layer) composite

Figure-15(c) show the composite with TF and RM subjected to steam treatment. Here breaking of fiber is not visible instead tearing of fiber along the surface has taken place. The traces of red mud are visible on the inter fiber spaces. Probably the presence of red mud somewhat restrict the swelling of fiber and hence breaking of fibers due to application of load.

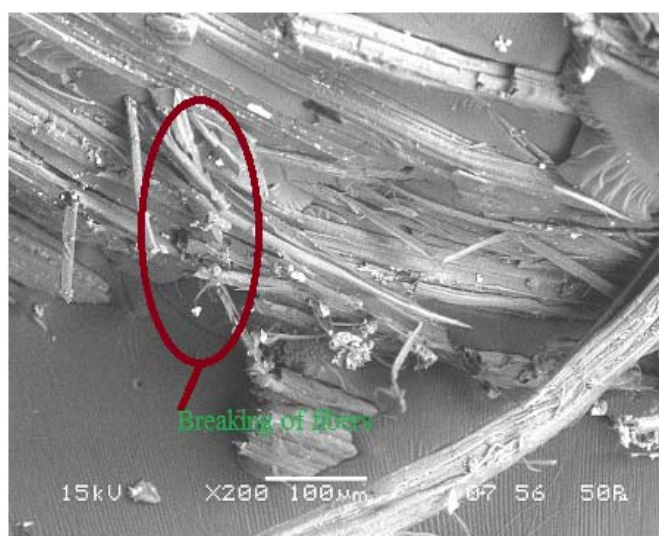

Figure 15(b). SEM micrograph of fractured surface of TF (single layered) composite

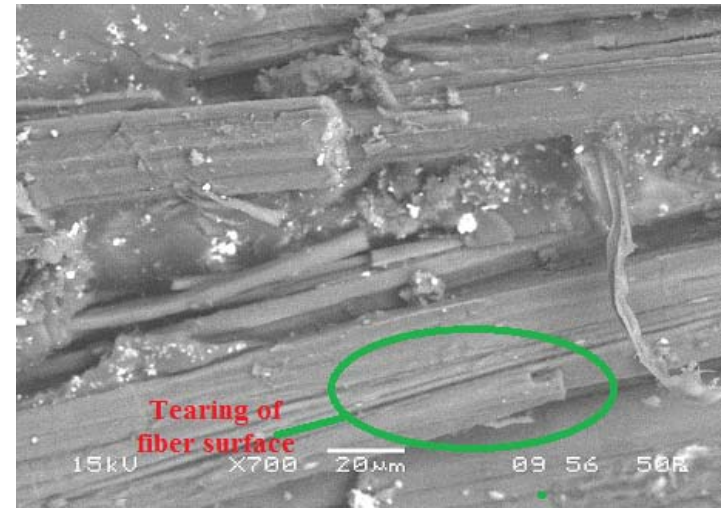

Figure 15(c). SEM micrograph of fractured surface of TF+RM (single layered) composite

Figure-16(a),(b) shows the composite with TF and RM for double and triple layer. Matrix cracking and debonding of fibers are clearly visible for double layer composite. The bending of fibers instead of pull out of fibers is clearly visible in fig. (b), which reflects an increased load transfer from matrix to fiber, as revealed from the triple layer composite. As pointed out by Ray et al. (2001) increased load transfer from the matrix to fiber is possible if failure due to fiber pull out is minimum. In our case probably the presence of red mud in the matrix is responsible for bending of fiber instead pull out from the matrix. 


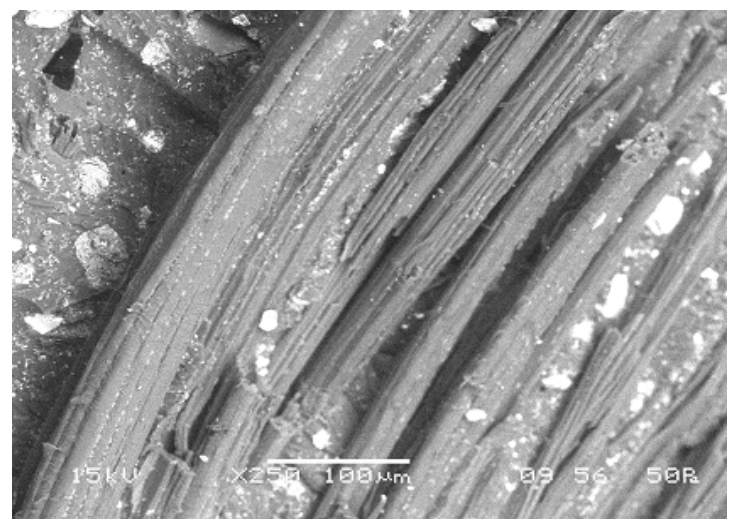

Figure 16(a). SEM micrograph of fractured surface of TF+RM (Double layered) composite

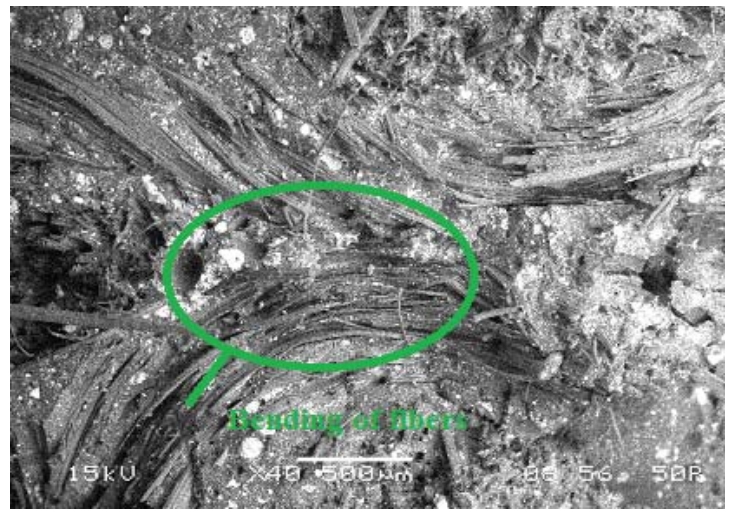

Figure 16(b). SEM micrograph of fractured surface of TF+RM (Triple layered) composite

In general fiber pull out is the predominant mode of failure for all natural fiber composites. The interfacial strength can be improved by treating the fiber surface by different chemical treatments. In our case fiber pull out is prevented and the failure mode is bending as seen from the micrographs. This might have happened due to addition of red mud particles in the matrix.

\section{Conclusions}

The following conclusions are drawn from the above studies.

- The composites reinforced with alkali treated jute fibers showed improved mechanical properties. The improvement was maximum for the composite prepared with 4 hrs alkali treated jute fibers.

- The flexural strength was found to be maximum for composites with treated fiber and red mud.

- Less percentage of water absorption was observed after the alkali treatment of fibers. This may be due to the chemical treatment which reduces the hydroxyl group in the cell wall of natural fiber molecules, thus decreasing the water absorption of the composite.

- The effect of red mud as far as strength is concerned is well visualized. It acts as a barrier due to which the moisture did not get a chance to attack the jute fiber and detoriate the strength.

- From the aesthetic point of view the fabricated composite promise a wide use in making doors, windows, panels, false roofing, floor tiles etc.

- From this work it is found that chemical modification of the fiber with alkali,significantly improves the mechanical performance of the composite. Other chemical modification methods such as silane treatment, acetylation treatment, isocynates treatment, permanganate treatment, maleated coupling agents could be tried and a final conclusion can be drawn thereafter.

\section{References}

Bledzki A.K., Gassan J. Composites Reinforced with Cellulose Based Fibers, Progress in Polymer Science, 1999, Vol. 24, No. 2, pp. 221-274. 
Bogoeva-Gaceva G., Avella M., Malinconico M., Buzarovska A., Grozdanov A., Gentile G., Errico M.E. 2007. Polymer Composites, Wiley Inter Science. Research, Vol. 40, pp. 222-237.

Espert, A., Vilaplana, F. and Karlsson, S., 2004, Comparison of water absorption in natural cellulosic fibres from wood and oneyear crops in polypropylene composites and its influence on their mechanical properties, Composite Part A ; Vol. 35, pp. 126776.

Fraga A.N., Frulloni E., De la Osa O, Kenny J.M., A., Vazquez. 2006. Relationship between water absorption and dielectric behaviour of natural fiber composites materials, Polymer Testing, Volume 25, p.181-187

Joseph P.V., Kuruvilla J., Thomas S. 1999. Effect of processing variables on the mechanical properties of sisal fiber reinforced polypropylene composites, Composites science and Technology, Vol. 59, No. 11, pp.1625-1640.

Joseph, K., Thomas, S. and Pavithran, C., 1996, "Effect of chemical treatment on the tensile properties of short sisal fibrereinforced polyethylene composites, Polymer, Vol. 37, pp. 5139-5149.

Joseph, P.V., Joseph, K. and Thomas, S., 1999, Effect of processing variables on the mechanical properties of sisal-fiberreinforced polypropylene composites, Composite Science and Technology, 59: pp.1625-40.

Jain S., Kumar R.,Jindal UC. 1992. Mechanical Behavior of Bamboo and Bamboo Composites, J. Mater. Sci., Vol. 27, pp. 45984604.

Maya Jacob John, Anandjiwala Rajesh D., 2008, Recent Developments in Chemical Modification and Characterization of Natural Fiber-Reinforced Composites, Polymer Composites, pp.187-207.

Mohanty A.K., Khan M.A., Hinrichsen G. Influence of chemical surface modification on the properties of biodegradable jute fabrics - polyester amide composites 2000. Composites, Part A Elsevier Science Ltd. 31,143-150.

Mukherjee P.S., Satyanarayana K.G., Structure and properties of some vegetable fibers-II. Pineapple leaf fiber,1986. MaterialScience, 21, 51-6.

Nishino T., Hirao K., Kotera M., Nakamae K., Inagaki H. 2003. Kenaf reinforced biodegradable composite. Composites Science and Technology, Vol.63, pp. 1281-1286..

Ray D., Sarkar B.K., Rana A.K., Bose N.R. 2001. The mechanical properties of vinylester resin matrix composites reinforced with alkali-treated jute fiber, Composites: Part A, Vol. 32, p. 119-127.

Rowell, R.M., 1997, Chemical modification of agro-resources for property enhancement, Paper and Composites from Agro-based Resources, CRC Press. pp. 351-375.

Satyanarayana K. G., Kulkarni A. G., Rohatgi P. K. Potential of natural fibres as a resource for industrial material in Kerala,1981 J.of Scientific \& Industrial, Vol. 40, No. 4, pp. 222-237

Sanadi, A.R., CaulField, D.F. and Jacobson, R.E., 1997, Agro-Fibre Thermoplastic Composites, Paper and composites from agro-based resources, Boca Raton: CRC Press: Lewis Publishers, Chapter 12, pp. 377-401.

Vazquez A., Dominguez V. A., Kenny J. M. 1999. Bagasse fiber-polypropylene based composites. Journal of Thermoplastic Composite Materials, Vol. 12, No. 6, pp. 477-497.

\section{Biographical notes}

Mr. B. C. Patel is an Assistant Professor in the Department of Mechanical Engineering, PIET, Rourkela, India.

Dr. S.K. Acharya is a Professor in the Department of Mechanical Engineering, National Institute of Technology Rourkela, India. He has more than 24years of experience in teaching and research. His current area of research includes Tribology, Composite materials and Nano Technology. He has published more than thirty papers in referred national and international journals. He has also presented more than seventy five research articles in national and international conferences.

Dr D. Mishra is a Professor in the Department of Manufacturing science and Engineering,VSSUT,Burla,Sambalpur.He has got 15 years of teaching experience. He has published more than twenty five papers in referred national and international journals. He has also presented more than forty five research articles in national and international conferences.

Received April 2012

Accepted November 2012

Final acceptance in revised form December 2012 